\title{
Drug Induced Sleep Endoscopy Identification of Adenoid Regrowth in Pediatric Obstructive Sleep Apnea
}

\author{
Habib G. Zalzal $\left(\mathbb{D},{ }^{1}\right.$ Michele Carr $\left(\mathbb{D},{ }^{1}\right.$ Nainika Nanda, ${ }^{2}$ and Steven Coutras ${ }^{1}$ \\ ${ }^{1}$ Department of Otolaryngology, Head and Neck Surgery, West Virginia University School of Medicine, Morgantown, WV, USA \\ ${ }^{2}$ West Virginia University School of Medicine, Morgantown, WV, USA \\ Correspondence should be addressed to Habib G. Zalzal; hgzalzal@hsc.wvu.edu
}

Received 19 November 2017; Revised 24 February 2018; Accepted 13 March 2018; Published 26 April 2018

Academic Editor: Leonard P. Rybak

Copyright (c) 2018 Habib G. Zalzal et al. This is an open access article distributed under the Creative Commons Attribution License, which permits unrestricted use, distribution, and reproduction in any medium, provided the original work is properly cited.

\begin{abstract}
Objective. To establish the incidence and possible contributing factors leading to adenoid regrowth in children with pediatric sleep apnea using drug induced sleep endoscopy (DISE). Methods. Children treated for obstructive sleep apnea following previous adenoidectomy were evaluated using DISE. Adenoid regrowth was scored by the same attending physician using a 5-point grading scale. Age, sex, body mass index (BMI) percent for age, polysomnogram results, initial adenoid size before adenoidectomy, and postoperative complications were evaluated. Results. Fifty-six patients (age range 22 months to 16 years) met inclusion criteria. Twenty-five children (44.6\%) had Grade 2 adenoid or larger. Mean age at the time of DISE was 7.11 years, with an average of 1.75 years since initial adenoidectomy. Mean preadenoidectomy size based on intraoperative nasopharyngeal mirror assessment was Grade 2.55 (95\% CI 2.30-2.79). Adenoid size at time of sleep endoscopy was Grade 1.64 (95\% CI 1.30-1.98). Characteristics associated with adenoid regrowth were higher body mass index for age percentile at time of endoscopy $(P<0.05)$, initial adenoid size $(P<0.01)$, and time between initial adenoidectomy and endoscopy $(P=0.05)$. Conclusions. Body mass index for age percentile, initial adenoid size, and time between initial adenoidectomy and drug induced sleep endoscopy correlate with regrowth in childhood obstructive sleep apnea.
\end{abstract}

\section{Introduction}

Adenoidectomy, with or without tonsillectomy, is one of the more frequently performed operations within otolaryngology, estimated to be about 129,540 operations per year in the United States $[1,2]$. Indications for adenoidectomy range from adenoid-induced obstruction of the nasopharynx to chronic infections of the middle ear, sinuses, and adenoid itself. Often, symptoms resolve following successful surgical intervention, but recurrence of symptoms with adenoid regrowth has been documented in $1-25 \%$ of patients who have an adenoidectomy [2-4].

Obstructive sleep apnea (OSA) affects $1-4 \%$ of children [5]. In children who require revision adenoidectomy, up to $94 \%$ of patients have symptoms associated with nasopharyngeal obstruction including snoring and sleep disturbance [6]. Children with persistent OSA following adenotonsillectomy may undergo drug induced sleep endoscopy (DISE) to identify the location of upper airway obstruction. In a sedated patient, DISE allows for identification of sites of obstruction of the upper respiratory tract during simulated sleep and complete visualization of the upper respiratory tract. DISE is an effective tool for surgical planning in children with persistent OSA after adenotonsillectomy or if their physical exam is not consistent with adenotonsillar hypertrophy [7].

This study uses DISE as the main diagnostic tool to determine the incidence of adenoid regrowth at our institution and identify risk factors associated with recurrent symptoms leading to revision adenoidectomy.

\section{Materials and Methods}

This study was a retrospective case series with chart review performed at a large tertiary academic facility following institutional review board approval. A computational search using the EPIC electronic medical record was performed for the term "flexible laryngoscopy for sleep endoscopy," consistent with the phrase used for DISE at our institution. 


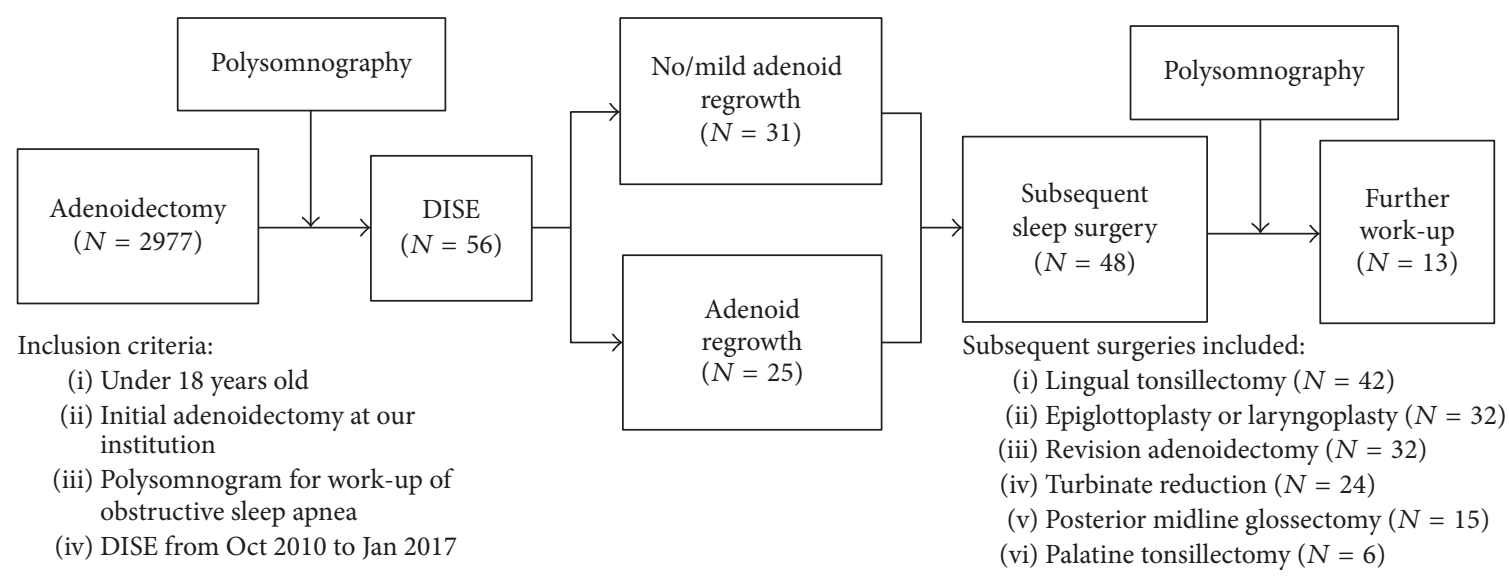

FIGURE 1: Methodology for inclusion criteria and data accumulation for obstructive sleep apnea patients undergoing drug induced sleep endoscopy (DISE).

Search was limited to patients under 18 years identified as having undergone polysomnography (PSG) prior to sleep endoscopy from October 13, 2010, to January 1, 2017 (Figure 1). All patients were managed by the same attending otolaryngologist. Sleep endoscopy was performed after a positive polysomnogram for sleep apnea with no obvious source of airway obstruction on physical exam.

Inclusion criteria involved children (age $<18$ years) who underwent primary adenoidectomy with or without tonsillectomy at our institution and subsequently required DISE for evaluation of PSG confirmed persistent obstructive sleep apnea. Patients were excluded if they previously had primary adenoidectomy at an outside facility or did not have documentation of adenoid size during primary adenoidectomy. Data extracted from the electronic medical record included gender, birthdate, initial adenoidectomy technique, adenoid size per surgical and endoscopic evaluations, date of adenoidectomy, date of sleep endoscopy, body mass index (BMI) and weight at the time of sleep endoscopy, allergic rhinitis/allergies, asthma, behavior disorders, developmental delay, reflux, other comorbidities, and subsequent sleep surgeries. Six different otolaryngologists with resident assistance were responsible for the initial adenoidectomy of the patients since electronic medical record keeping began at this institution in 2009. Adenoidectomies were performed for a variety of reasons, the majority for OSA, but also for middle ear disease and chronic adenoiditis. Techniques employed included suction electrocautery or coblation of the adenoid tissue.

Diagnosis of medical conditions (allergies, asthma, etc.) was based on their presence either in the medical notation by the treating otolaryngologist or within the medical record via International Classification of Diseases, Tenth Revision (ICD10) codification at the time of initial sleep endoscopy. Adenoid size at the time of primary adenoidectomy (preoperative adenoid size) was obtained from the operative notes. Adenoid size at DISE was subjectively graded by the same attending surgeon using a descriptive scale used at our institution and reported in the operative note (Figure 2). An adenoid size of Grade 0 signifies $0 \%$ obstruction of the choanae with likely presence of scarring, Grade 1 signifies $<40 \%$ obstruction, Grade 2 signifies $41-70 \%$ obstruction, Grade 3 signifies 71-90\% obstruction, and Grade 4 signifies complete obstruction (91-100\%) of the choanae with lymphoid tissue touching the soft palate at rest.

BMI for age percentile was separated into four groups: "underweight" if BMI was less than the 25th percentile, "normal weight" if between 25 and 84.9\%, "overweight" if between 85 and $94.9 \%$, and "obese" if in the 95 th percentile or greater. Adenoid regrowth was present if endoscopic visualization of the adenoid showed a Grade 2 or larger adenoid on postadenoidectomy DISE. All children undergoing revision adenoidectomy had an adenoid of Grade 2 or larger.

Statistical evaluation was executed using $I B M^{\circledR}$ SPSS Statistics ${ }^{\circledR}$ (Version 24.0. Armonk, NY: IBM Corp) software. Chi-square analysis was performed for nominal data with Pearson's correlation, while independent samples t-tests were performed for interval data (time between procedures and age characteristics). Ordinal data (BMI, adenoid size) was analyzed using Kruskal Wallis testing and Spearman's Rho correlation. Statistical significance was defined as $P \leq 0.05$.

\section{Results}

Fifty-six patients (age range 22 months to 16 years) met the inclusion criteria for having undergone primary adenoidectomy prior to DISE. Table 1 summarizes the demographic data of these patients. Mean age at the time of DISE was 7.11 years, with an average of 1.75 years since initial adenoidectomy. Many children in our study had a BMI greater than the 95th percentile for age (46.4\%). Allergic rhinitis was common in this population $(46.4 \%)$. For behavioral issues, the majority of diagnoses were attention deficit disorder (ADHD) and oppositional defiant disorder (ODD). Subsequent sleep surgery was performed after DISE in $86 \%$ of patients (Figure 1).

Adenoid characteristics are described in Table 2. The mean initial adenoid size based on preoperative assessment was Grade 2.55 (95\% CI 2.30-2.79). Upon postoperative DISE, this improved to Grade 1.64 (95\% CI 1.30-1.98). The 


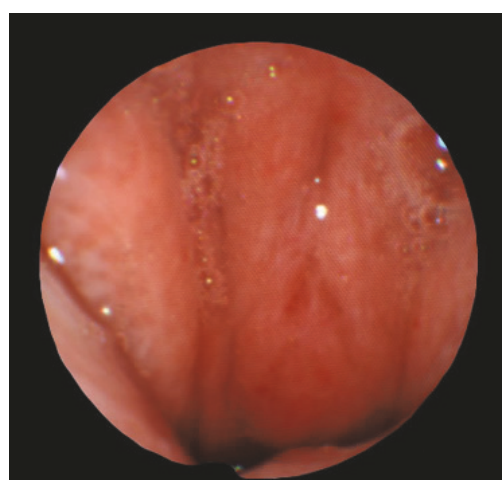

(a)

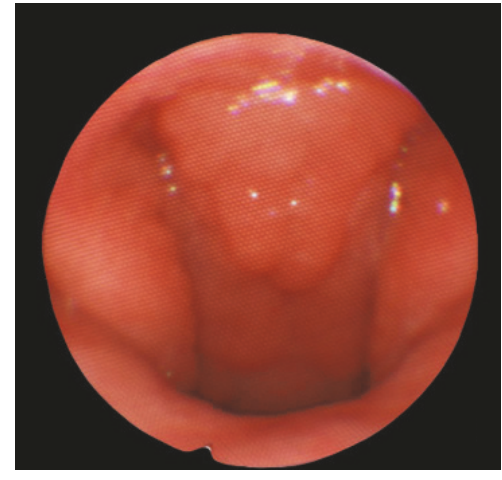

(b)

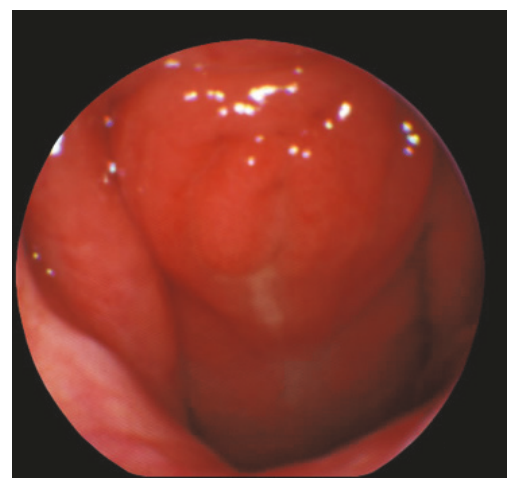

(c)

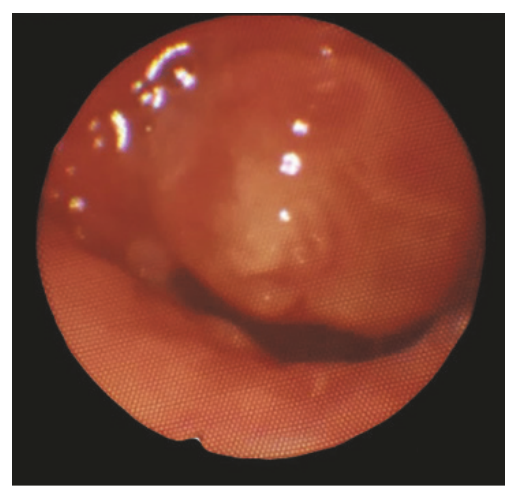

(d)

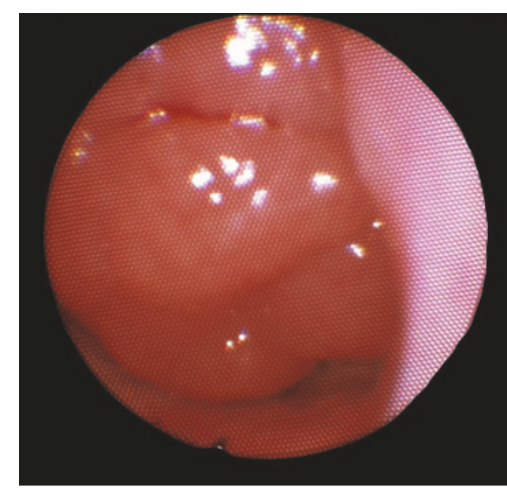

(e)

FIGURE 2: Adenoid hypertrophy grading system used at West Virginia University for Drug Induced Sleep Endoscopy. Grade 0 (0\%) (a), Grade $1(<40 \%)$ (b), Grade 2 (41\%-70\%) (c), Grade 3 (71\%-90\%) (d), and Grade 4 (91\%-100\%) (e).

incidence of regrowth as determined by DISE was $44.6 \%$, and subsequently 32 patients underwent revision adenoidectomy. Factors associated with adenoid regrowth are summarized in Table 3: greater BMI percentile at the time of DISE (Kruskal Wallis $\chi^{2}=5.559, P<0.05$; Figure 3), larger initial adenoid size (Kruskal Wallis $\chi^{2}=7.013, P<0.01$; Figure 4 ), and increased time between initial adenoidectomy and DISE ( $F$ Statistic $=3.90, P=0.05 ; 95 \% \mathrm{CI}-1.70$ to -0.06 ).

Adenoid regrowth had no significant correlation with other comorbidities, surgical technique, and initial surgery. Demographic data, age, and prior surgeries to adenoid size at first DISE were also not significant.

\section{Discussion}

Studies have shown that up to $94 \%$ of patients undergoing adenoid revision had problems with snoring, congestion, and noisy breathing prior to surgery [6]. However, other studies have demonstrated that most patients with adenoid regrowth up to about $40 \%$ obstruction are asymptomatic $[3,8]$. Therefore, opinions exist that the recurrent obstructive symptoms in children with adenoid regrowth are due to underlying risk factors, such as age, body mass index, gender, and reflux, rather than the adenoid [9].

In our patient population of children with persistent OSA, $57 \%$ of patients underwent revision adenoidectomy. These patients presented with persistent symptoms and therefore represent a population more likely to have upper airway obstruction. This group has a higher rate of adenoid revision compared to other studies in the literature which focus on revision rate alone. A 2012 retrospective review of patients with mostly obstructive adenoids found the revision rate to be $2.2 \%$ of total pediatric adenoidectomies at 5 years and $3 \%$ at 10 years, with a higher risk of requiring revision in patients who had their first surgery at an earlier age [9]. However, our population was at risk for higher adenoid regrowth rates, since all subjects presented with persistent OSA. Similarly, a prospective analysis of 68 children with recurrent adenotonsillitis showed correlation between age and incidence of regrowth via transnasal endoscopy, with the most regrowth occurring in the group under age of 5 years [4]. Our study found no such relation between age and rate of regrowth as determined by DISE (Table 3, $P=$ 0.31 ). Other studies have also demonstrated larger adenoid hypertrophy in younger children, especially those under age 5 years, and these children were most likely to undergo revision adenoidectomy $[9,10]$. Age was an insignificant factor within our population most likely because DISE occurred after this natural growth period (7.11 years) $[9,10]$.

Significance was obtained when comparing elapsed time between initial adenoidectomy and first evaluation by DISE (Table 3, $P=0.05$ ). Patients who had endoscopic visualization of their adenoid tissue soon after surgery would be unlikely to have regrowth compared to those with DISE in a 
TABLE 1: Demographics and clinical characteristics of pediatric OSA patients undergoing DISE after previous adenoidectomy.

\begin{tabular}{|c|c|c|}
\hline Variable & $N$ & $\%$ \\
\hline \multicolumn{3}{|l|}{ Gender } \\
\hline Male & 35 & 62.5 \\
\hline Female & 21 & 37.5 \\
\hline \multicolumn{3}{|l|}{ Age (mean $\pm 95 \%$ CI, years) } \\
\hline Initial adenoidectomy & $5.36 \pm 0.91$ & - \\
\hline First DISE & $7.11 \pm 0.93$ & - \\
\hline \multicolumn{3}{|l|}{ Timeframe (mean $\pm 95 \%$ CI, years) } \\
\hline Time between initial adenoidectomy and DISE & $1.75 \pm 0.39$ & - \\
\hline Time between adenoidectomies & $2.37 \pm 0.45$ & - \\
\hline \multicolumn{3}{|l|}{ Mean AHI (mean \pm 95\% CI, events/hour) } \\
\hline Pre-DISE & $8.53 \pm 4.5$ & \\
\hline Improvement after DISE-related surgery & $-6.33 \pm 5.9$ & \\
\hline \multicolumn{3}{|l|}{ BMI for age percentile at first DISE } \\
\hline Group 1 underweight $(<25 \%)$ & 7 & 12.5 \\
\hline Group 2 normal weight $(25 \%$ to $<85 \%)$ & 18 & 32.1 \\
\hline Group 3 overweight ( $85 \%$ to $<95 \%)$ & 5 & 8.9 \\
\hline Group 4 obese $(95 \%+)$ & 26 & 46.4 \\
\hline \multicolumn{3}{|l|}{ Comorbid conditions at time of first DISE } \\
\hline Allergic rhinitis & 26 & 46.4 \\
\hline Asthma & 20 & 35.7 \\
\hline Developmental delay ${ }^{\dagger}$ & 16 & 28.6 \\
\hline Reflux & 18 & 32.1 \\
\hline Behavioral disorders & 18 & 32.1 \\
\hline Hypertension & 5 & 8.9 \\
\hline Laryngomalacia & 6 & 10.7 \\
\hline Follow-up sleep surgery after DISE & 48 & 85.7 \\
\hline
\end{tabular}

OSA, obstructive sleep apnea; DISE, drug induced sleep endoscopy; CI, confidence interval; AHI, apnea-hypopnea index; BMI, body mass index. ${ }^{\dagger}$ Secondary to autism, hypotonia, muscular dystrophy, trisomy 21, trisomy 12, fragile $\mathrm{X}$, and etiology unknown.

later timeframe. Previous studies have shown adenoid size to increase for up to the first 12 years of life, consistent with this finding [2].

Our study found a relationship between adenoid size at initial surgery and adenoid regrowth (Table 3, Figure 4, $P<0.01)$. There was more obstruction at the time of initial surgery ( $40 \%$ with a Grade 2 adenoid) compared to obstruction at DISE (16.1\% with Grade 2 adenoid). This is consistent with data published by Kim et al., who used cephalometric studies to determine that preoperative adenoid size was a predictor of regrowth [10]. Pediatric patients with Grade 2 or larger adenoids are more likely to experience regrowth compared to those who had a Grade 1 adenoid at the time of initial surgery, likely due to greater potential of adenoid growth in these children compared to patients with inherently smaller adenoid at first evaluation [10].

While some of these findings are consistent with what is known in the literature, specifically for technique and allergic rhinitis [9-13], other factors are not. An 11-year retrospective review of adenoidectomies found esophageal reflux disease in $40 \%$ of those undergoing revision surgery [5]. Children undergoing adenoidectomy alone were noted to be four times more likely to need revision compared to those who underwent an adenotonsillectomy [14]. Neither of these factors was significant in our study. In addition, while both ADHD and ODD have been associated with pediatric OSA, behavioral issues were not significant for adenoid regrowth either (Table 3, $P=0.083$ ) [15].

Age percentile of BMI at time of first DISE was a notable predictor for regrowth in our patient population (Figure 3, $P<0.05)$. By contrast, other studies have noted no significant association between BMI and adenoid regrowth [10]. It is important to note that West Virginia has a high prevalence of obesity compared to other parts of the United States [16]. Nearly $50 \%$ of our study population was in the 95 th percentile for BMI by age. Although no study to date has determined the relationship between $\mathrm{BMI}$ and adenoid regrowth, nitric oxide has previously been theorized to play a role in obese children with sleep apnea. Nitric oxide serves as a marker of airway inflammation [17]. Levels of expired nitric oxide are found at higher levels in children with obesity and sleep apnea, but not when compared to normal weight children with sleep apnea or obese children without sleep apnea $[17,18]$. While adenoid size itself does not correlate with elevated nitric oxide levels [19], further work is needed to determine the association of adenoid regrowth to obese children with sleep apnea.

Within our population of persistently symptomatic patients, $44.6 \%$ of patients exhibited adenoid regrowth. 
TABLE 2: Adenoid characteristics.

\begin{tabular}{|c|c|c|}
\hline Variable & $N$ & $\%$ \\
\hline \multicolumn{3}{|l|}{ Initial adenoidectomy technique } \\
\hline Suction electrocautery & 47 & 83.9 \\
\hline Coblation & 9 & 16.1 \\
\hline \multicolumn{3}{|l|}{ Initial surgery } \\
\hline Tonsillectomy and adenoidectomy & 47 & 83.9 \\
\hline Adenoidectomy & 9 & 16.1 \\
\hline Preoperative adenoid size (mean $\pm 95 \% \mathrm{CI}$ ) & $2.55 \pm 0.24$ & \\
\hline Grade $0 ; 0 \%$ & 0 & 0 \\
\hline Grade $1 ;<40 \%$ & 7 & 13.5 \\
\hline Grade $2: 41 \%-70 \%$ & 21 & 40.4 \\
\hline Grade $3 ; 71 \%-90 \%$ & 18 & 34.6 \\
\hline Grade $4 ; 91 \%-100 \%$ & 10 & 19.2 \\
\hline Postoperative adenoid size by DISE (mean $\pm 95 \% \mathrm{CI}$ ) & $1.64 \pm 0.33$ & \\
\hline Grade $0 ; 0 \%$ & 11 & 19.6 \\
\hline Grade $1 ;<40 \%$ & 20 & 35.7 \\
\hline Grade $2 ; 41 \%-70 \%$ & 9 & 16.1 \\
\hline Grade 3; 71\%-90\% & 10 & 17.9 \\
\hline Grade 4; 91\%-100\% & 6 & 10.7 \\
\hline Regrowth as determined by DISE & 25 & 44.6 \\
\hline \# undergoing revision adenoidectomy & 32 & 57.1 \\
\hline
\end{tabular}

DISE, drug induced sleep endoscopy; CI, confidence interval.

TABLE 3: Factors associated with adenoid regrowth as determined by DISE.

\begin{tabular}{|c|c|c|c|}
\hline Variable & Regrowth & Absent/mild adenoid & $P$ value \\
\hline Males/females, \% & $60.0 / 40.0$ & $64.5 / 34.5$ & 0.73 \\
\hline Diagnosis of allergic rhinitis, $\%$ & 56.0 & 38.7 & 0.20 \\
\hline Diagnosis of asthma, \% & 40.0 & 32.3 & 0.55 \\
\hline Diagnosis of behavioral issues, $\%$ & 20.0 & 41.9 & 0.08 \\
\hline Diagnosis of developmental delay, $\%$ & 20.0 & 35.5 & 0.20 \\
\hline Diagnosis of reflux, \% & 32.0 & 32.3 & 0.98 \\
\hline Initial Adenoid Size, Grades 0-4 (mean \pm 95\% CI) & $2.77 \pm 0.42$ & $2.23 \pm 0.33$ & ${ }^{\dagger} 0.01$ \\
\hline BMI percentile, groups $1-4$ per Table $1($ mean $\pm 95 \%$ CI) & $3.28 \pm 0.39$ & $2.56 \pm 0.42$ & ${ }^{\dagger} 0.02$ \\
\hline Prior surgery adenoidectomy only, $\%$ & 8.0 & 22.6 & 0.14 \\
\hline coblation technique, $\%$ & 8.0 & 22.6 & 0.14 \\
\hline Age at adenoidectomy, mean $\pm 95 \%$ CI & $5.12 \pm 1.04$ & $5.55 \pm 1.52$ & 0.31 \\
\hline Age at DISE, mean $\pm 95 \%$ CI & $7.36 \pm 1.11$ & $6.91 \pm 1.56$ & 0.19 \\
\hline Time between adenoidectomy \& DISE, mean $\pm 95 \%$ CI & $2.24 \pm 0.59$ & $1.36 \pm 0.52$ & ${ }^{*} 0.05$ \\
\hline
\end{tabular}

DISE, drug induced sleep endoscopy; CI, confidence interval; BMI, body mass index. ${ }^{\dagger}$ Significance with Kruskal-Wallis test. ${ }^{*}$ Significance with independent samples $T$-testing.

Interestingly, most of these patients required a lingual tonsillectomy $(N=42 ; 75 \%)$ or laryngoplasty $(N=32,57 \%)$ to resolve their airway obstruction, in addition to revision adenoidectomy $(N=32,57 \%)$ at the time of other procedures. Overall $85.7 \%$ of patients underwent further surgery after sleep endoscopy. Other studies have demonstrated that adenotonsillectomy is often not curative for OSA, particularly in children who are older than 7 years or obese [20]. These findings are consistent with our study, confirming the value of DISE to locate other sources of obstruction in order to plan for further surgical intervention to reduce AHI in children with persistent disease [21]. Adenoid regrowth is unlikely to be the sole site of their airway obstruction during sleep.

A significant factor that could not be controlled in our study was surgical technique used for primary adenoidectomy, which may affect the incidence and degree of regrowth [11]. Since initial adenoidectomy was performed by six different otolaryngologists, surgical technique differed widely. Whether all adenoid tissue was removed could not be ascertained from the operative reports. Previous studies have shown that rate of adenoid regrowth is greatly reduced with adenoid removal down to the pharyngobasilar surface [13]. 


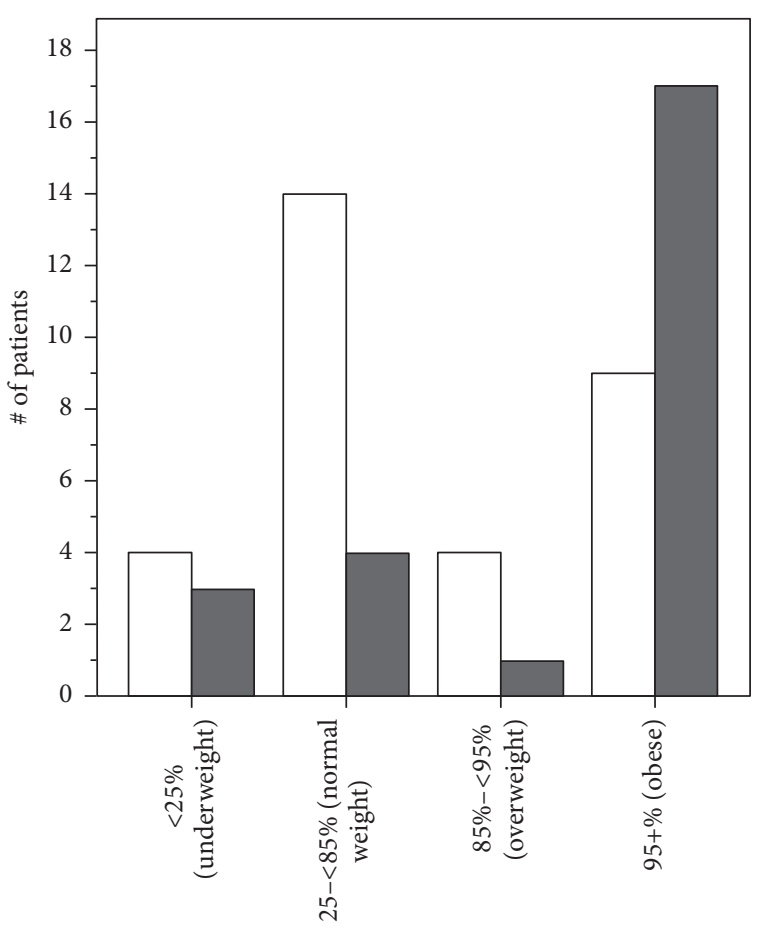

BMI for age percentile (\%) at 1st DISE

$$
\begin{aligned}
& \text { Regrowth } \\
& \text { of adenoid } \\
& \square \text { Absent/mild } \\
& \square \text { Regrowth }
\end{aligned}
$$

FIGURE 3: Relationship of body mass index (BMI) for age percentile with incidence of adenoid regrowth $(P<0.05)$.

Our study had a relatively small sample size since we only included children with OSA who underwent DISE. This limits the power of the study to detect small differences.

Our group uses an adenoid size grading approach similar to that used in a 2011 study comparing endoscopic versus soft tissue lateral X-ray adenoid size. They used a 4-category endoscopic adenoid size grading scale based on percent of choanal obstruction [22]. We questioned whether adenoid size as judged by mirror exam was similar to size judged by nasal endoscopy. A study looking at 28 patients undergoing adenoidectomy found consistent correlation $(P<$ 0.01 ) between adenoid size determined by endoscopy versus nasopharyngeal mirror examination [23]. Nevertheless, while our methods are not identical to other grading scales in the literature, endoscopic visualization of the adenoid is a useful tool for evaluating adenoid size in comparison with nasopharyngeal mirror exam [7].

\section{Conclusions}

Adenoidectomy remains a valuable procedure for children with sleep apnea. Our study found that initial adenoid size, BMI for age percentile, and time between adenoidectomy and DISE are the only significant predictors of subsequent adenoid regrowth in childhood obstructive sleep apnea. However, adenoid regrowth was not a major contributor to

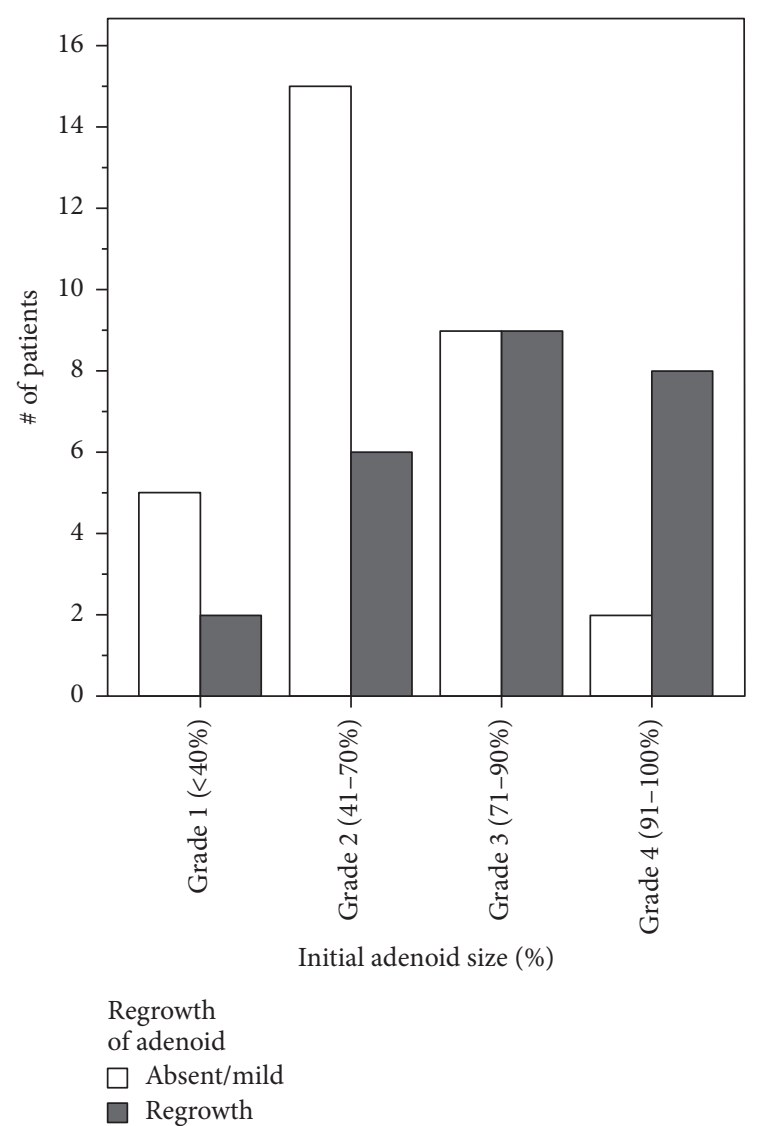

FIGURE 4: Relationship between initial adenoid size with subsequent adenoid regrowth $(P<0.01)$.

airway obstruction in $55.4 \%$ of children with obstructive sleep apnea, as over half of our patients needed surgery upon the hypopharyngeal or laryngeal airway as well in order to improve outcomes. This fact argues against revision adenoidectomy without sleep endoscopy in children with persistent OSA after adenotonsillectomy.

\section{Disclosure}

This research was initially presented as an oral presentation at 2017 AAO-HNSF Annual Meeting \& OTO Experience, Chicago, Illinois, on September 10, 2017.

\section{Conflicts of Interest}

The authors deny any conflicts of interest or funding sources associated with this research study.

\section{References}

[1] N. Bhattacharyya and H. W. Lin, "Changes and consistencies in the epidemiology of pediatric adenotonsillar surgery, 19962006," Otolaryngology-Head and Neck Surgery, vol. 143, no. 5, pp. 680-684, 2010.

[2] C. R. Grindle, R. C. Murray, S. K. Chennupati, P. C. Barth, and J. S. Reilly, "Incidence of revision adenoidectomy in children," The Laryngoscope, vol. 121, no. 10, pp. 2128-2130, 2011. 
[3] B. Joshua, G. Bahar, J. Sulkes, T. Shpitzer, and E. Raveh, "Adenoidectomy: Long-term follow-up," Otolaryngology-Head and Neck Surgery, vol. 135, no. 4, pp. 576-580, 2006.

[4] E. Lesinskas and M. Drigotas, "The incidence of adenoidal regrowth after adenoidectomy and its effect on persistent nasal symptoms," European Archives of Oto-Rhino-Laryngology, vol. 266, no. 4, pp. 469-473, 2009.

[5] J. C. Lumeng and R. D. Chervin, "Epidemiology of pediatric obstructive sleep apnea," Proceedings of the American Thoracic Society, vol. 5, no. 2, pp. 242-252, 2008.

[6] A. Monroy, P. Behar, and L. Brodsky, "Revision adenoidectomyA retrospective study," International Journal of Pediatric Otorhinolaryngology, vol. 72, no. 5, pp. 565-570, 2008.

[7] D. K. Chan, B. J. Liming, D. L. Horn, and S. R. Parikh, "A new scoring system for upper airway pediatric sleep endoscopy," JAMA Otolaryngology - Head and Neck Surgery, vol. 140, no. 7, pp. 595-602, 2014.

[8] F. J. Buchinsky, M. A. Lowry, and G. Isaacson, "Do adenoids regrow after excision?" Otolaryngology-Head and Neck Surgery, vol. 123, no. 5, pp. 576-581, 2000.

[9] A. C. Dearking, B. D. Lahr, A. Kuchena, and L. J. Orvidas, "Factors associated with revision adenoidectomy," Otolaryngology Head and Neck Surgery (United States), vol. 146, no. 6, pp. 984990, 2012.

[10] S. Y. Kim, W.-H. Lee, C.-S. Rhee, C. H. Lee, and J.-W. Kim, "Regrowth of the adenoids after coblation adenoidectomy: Cephalometric analysis," The Laryngoscope, vol. 123, no. 10, pp. 2567-2572, 2013.

[11] A. Sapthavee, B. Bhushan, E. Penn, and K. R. Billings, "A comparison of revision adenoidectomy rates based on techniques," Otolaryngology - Head and Neck Surgery (United States), vol. 148, no. 5, pp. 841-846, 2013.

[12] V. Agrawal, P. K. Agarwal, and A. Agrawal, "Defining the Surgical Limits of Adenoidectomy so as to Prevent Recurrence of Adenoids," Indian Journal of Otolaryngology and Head \& Neck Surgery, vol. 68, no. 2, pp. 131-134, 2016.

[13] L. Wei, M. Wang, N. Hua, K. Tong, L. Zhai, and Z. Wang, "Regrowth of the adenoids after adenoidectomy down to the pharyngobasilar fascial surface," The Journal of Laryngology \& Otology, vol. 129, no. 7, pp. 662-665, 2015.

[14] M. Duval, J. C.-S. Chung, and J.-P. Vaccani, "A case-control study of repeated adenoidectomy in children," JAMA Otolaryngology - Head and Neck Surgery, vol. 139, no. 1, pp. 32-36, 2013.

[15] K. Bartholomew and J. Owens, "Sleep and ADHD: a review.," Rhode Island Medical Journal, vol. 89, no. 3, pp. 91-93, 2006.

[16] C. L. Ogden, M. D. Carroll, B. K. Kit, and K. M. Flegal, "Prevalence of childhood and adult obesity in the United States, 2011-2012," The Journal of the American Medical Association, vol. 311, no. 8, pp. 806-814, 2014.

[17] S. L. Verhulst, N. Schrauwen, D. Haentjens et al., "Sleepdisordered breathing in overweight and obese children and adolescents: Prevalence, characteristics and the role of fat distribution," Archives of Disease in Childhood, vol. 92, no. 3, pp. 205-208, 2007.

[18] S. L. Verhulst, L. Aerts, S. Jacobs et al., "Sleep-disordered breathing, obesity, and airway inflammation in children and adolescents," CHEST, vol. 134, no. 6, pp. 1169-1175, 2008.

[19] S. Torretta, P. Marchisio, S. Esposito et al., "Exhaled nitric oxide levels in children with chronic adenotonsillar disease," International Journal of Immunopathology and Pharmacology, vol. 24, no. 2, pp. 471-480, 2011.
[20] R. Bhattacharjee, L. Kheirandish-Gozal, K. Spruyt et al., "Adenotonsillectomy outcomes in treatment of obstructive sleep apnea in children: A multicenter retrospective study," American Journal of Respiratory and Critical Care Medicine, vol. 182, no. 5, pp. 676-683, 2010.

[21] M. T. Truong, V. G. Woo, and P. J. Koltai, "Sleep endoscopy as a diagnostic tool in pediatric obstructive sleep apnea," International Journal of Pediatric Otorhinolaryngology, vol. 76, no. 5, pp. 722-727, 2012.

[22] B. Saedi, M. Sadeghi, M. Mojtahed, and H. Mahboubi, "Diagnostic efficacy of different methods in the assessment of adenoid hypertrophy," American Journal of Otolaryngology - Head and Neck Medicine and Surgery, vol. 32, no. 2, pp. 147-151, 2011.

[23] E. J. Chisholm, S. Lew-Gor, D. Hajioff, and H. Caulfield, "Adenoid size assessment: A comparison of palpation, nasendoscopy and mirror examination," Clinical Otolaryngology, vol. 30, no. 1, pp. 39-41, 2005. 


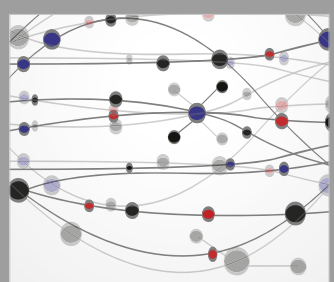

The Scientific World Journal
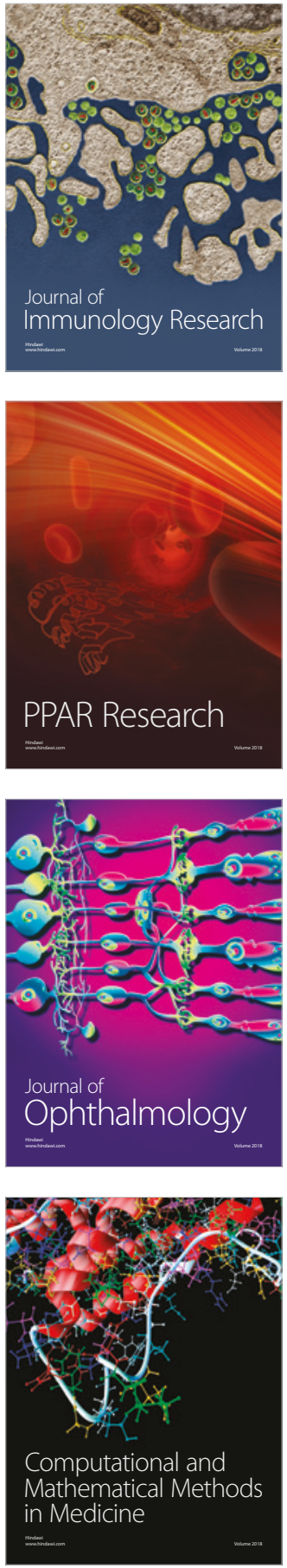

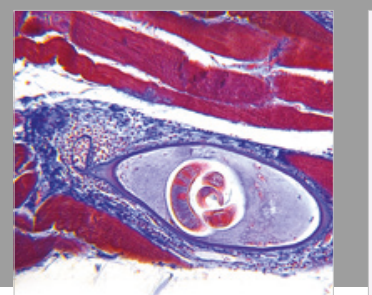

Gastroenterology Research and Practice

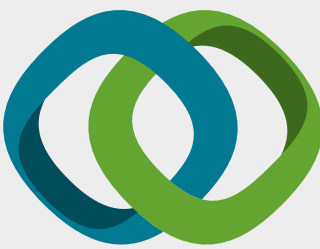

\section{Hindawi}

Submit your manuscripts at

www.hindawi.com
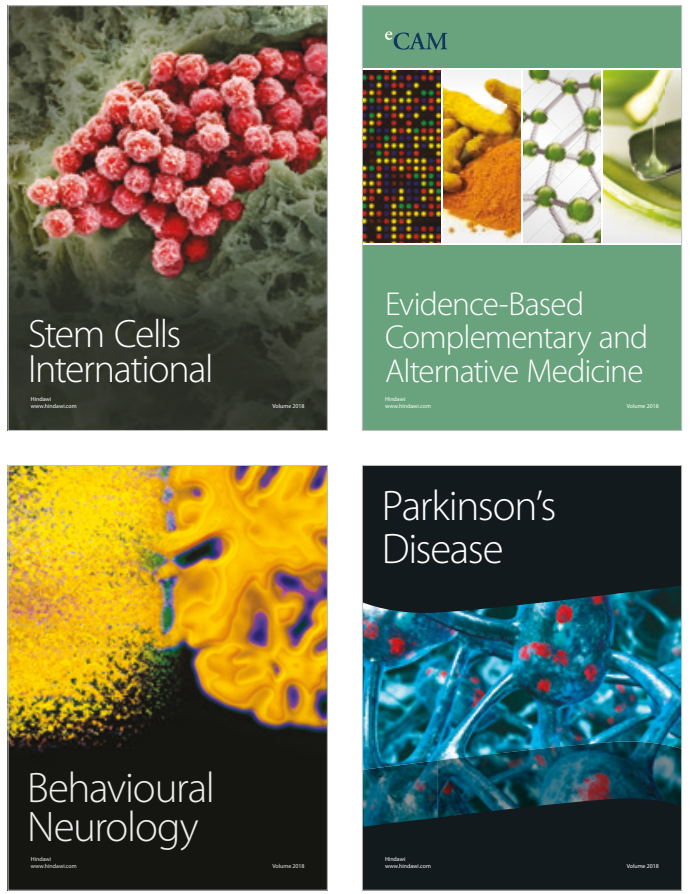

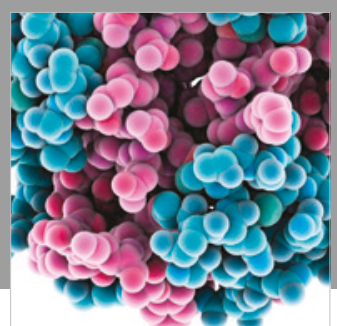

ournal of

Diabetes Research

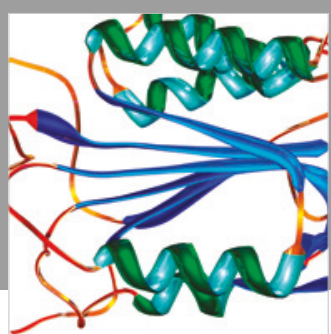

Disease Markers
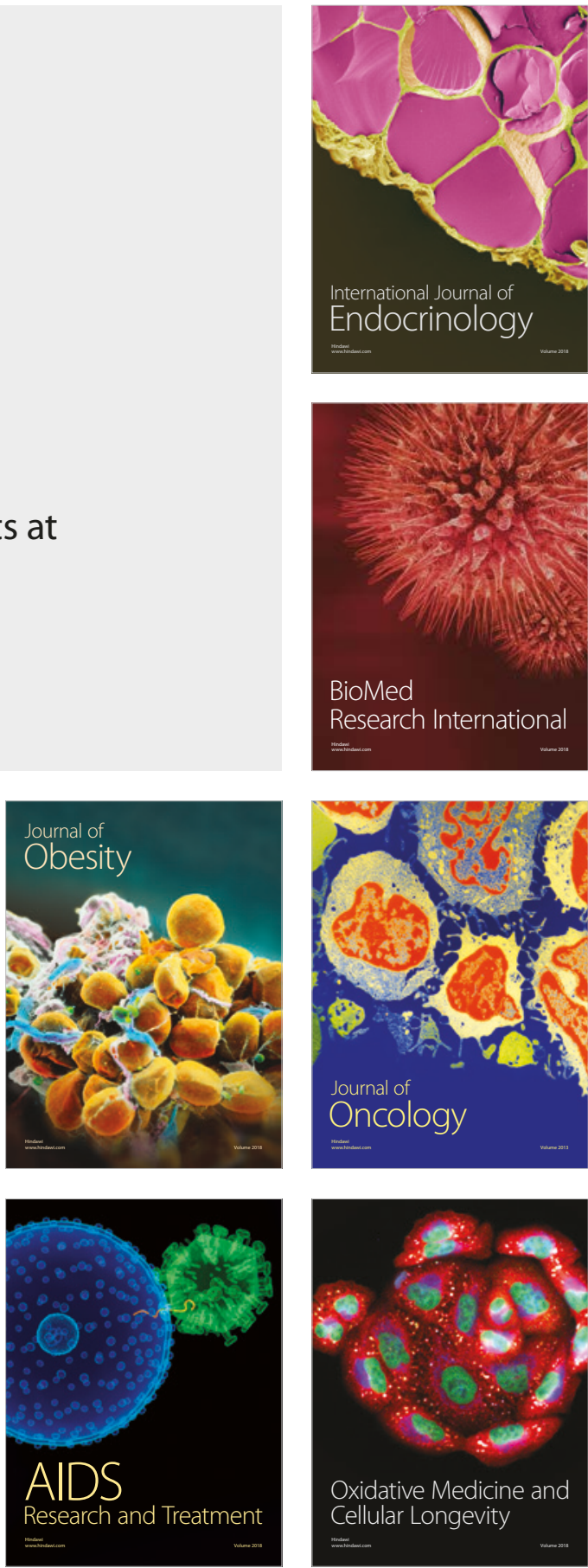